DOI: 10.12957/demetra.2017.28064

\title{
Contribuições da extensão universitária para a construção de conhecimento em segurança alimentar e nutricional
}

\section{Contributions of the university outreach to the construction of knowledge in food and nutrition security}

Elaine Martins Pasquim?

Elisabetta Recine ${ }^{2}$

1 Universidade de Brasília, Faculdade de Ciências da Saúde, Departamento de Nutrição. BrasíliaDF, Brasil.

${ }^{2}$ Universidade de Brasília, Faculdade de Ciências da Saúde, Departamento de Nutrição. Observatório de Políticas de Saúde Alimentar e Nutrição. Brasilia-DF, Brasil.

Este trabalho teve apoio do Edital ProlC/ DPP/UnB - Programa de Iniciação Científica da Universidade de Braślia-PIBIC (CNPq) 2014/2015

Correspondência / Correspondence Elaine Martins Pasquim

E-mail: elaine.pasquim@gmail.com

\section{Resumo}

A reflexão sobre a segurança alimentar e nutricional a partir da extensão universitária contribui para a compreensão sobre a construção do conhecimento nesta área na relação entre universidade e sociedade. O objetivo deste estudo foi identificar elementos de diferentes paradigmas da ciência na construção de conhecimento na extensão em segurança alimentar e nutricional. Foram identificadas propostas financiadas por editais do Programa Nacional de Extensão Universitária do Ministério da Educação. Realizou-se análise documental, considerando-se as seguintes categorias empíricas: princípios da extensão, foco dos projetos de extensão, relação com a sociedade, instrumentos/ estratégias usadas. Grande parte das propostas analisadas explicita o objetivo de promover o diálogo entre saberes científicos e populares; de modo interdisciplinar; com compromisso social; na interação com múltiplos atores e com políticas públicas; promovendo a sustentabilidade e o desenvolvimento de tecnologias sociais. Aproximam-se, em geral, de uma abordagem de ciência para o bem da sociedade. Entretanto, percebe-se que paradigmas diferentes convivem na extensão na área. Algumas propostas expressam uma visão mais linear na relação da ciência e tecnologia com a sociedade, como iniciativas que visam à transmissão de conhecimento e tecnologia. A extensão pode favorecer uma ciência em segurança alimentar e nutricional comprometida com o diálogo e redução de desigualdades, porém, ainda é necessário que as universidades aprofundem as reflexões sobre os princípios que orientam suas práticas, quanto 
à abordagem de ciência e tecnologia, ao tipo de desenvolvimento tecnológico esperado e à relação com a sociedade.

Palavras-chave: Segurança Alimentar e Nutricional. Educação Superior. Extensão Comunitária.

\section{Abstract}

Reflection on food and nutrition security from the perspective of university outreach contributes to the understanding about the construction of knowledge in this area, in the relation between university and society. The objective of this study was to identify elements of different paradigms of science in the construction of knowledge in the outreach in food and nutrition security. Proposals financed by the Brazilian National Outreach Program of the Ministry of Education of Brazil were identified. Content analysis was carried out, considering the following empirical categories: principles of outreach, focus of outreach projects, relationship with society, instruments/ strategies used. Most of the proposals analyzed intend to promote dialogue between scientific and popular knowledge, in an interdisciplinary way, with social commitment, in interaction with multiple actors and with public policies, promoting the sustainability and development of social technologies. However, it can be seen that different paradigms coexist in this outreach area. Some proposals express a more linear vision in the relation of science and technology with society, as initiatives that aim at the transmission of knowledge and technology. Outreach can foster science in food and nutrition security committed to dialogue and reduction of inequalities, but it is still necessary for universities to deepen their reflections on the principles that guide their practices, regarding the approach of science and technology used, the type of technological development expected and the relationship with society.

Keywords: Food and Nutrition Security. Higher Education. University Outreach. 


\section{Introdução}

O Fórum de Pró-reitores das Universidades Públicas Brasileiras(Forproex) definiu, em 1987, que "extensão universitária é o processo educativo, cultural e científico que articula o ensino e a pesquisa de forma indissociável e viabiliza a relação transformadora entre Universidade e Sociedade". Este conceito de extensão universitária se compatibiliza com a proposta de Boaventura de Sousa Santos quanto à realização de uma ciência capaz de valorizar experiências, construindo conhecimentos capazes de transformar o mundo, por meio de um verdadeiro diálogo entre vozes que emergem dos territórios e grupos acadêmicos engajados. ${ }^{2}$ Também é congruente com a proposta de Minayo, ${ }^{3}$ quando diz que:

Atuar em projetos sociais significa potencializar mudanças nas esferas essenciais em direção dos valores universais de desenvolvimento humano (...). A reflexão aqui iniciada (...) conjuga com as transformações em nível de consciência individual e com as mudanças dos processos coletivos.

Para Velho, ${ }^{4}$ há quatro paradigmas da ciência, quais sejam: (1) ciência como motor do progresso; (2) ciência como solução e causa de problemas; (3) ciência como fonte de oportunidade estratégica; (4) ciência para o bem da sociedade. Para cada paradigma, estão envolvidos conceitos dominantes de ciência, que contemplam: quem produz o conhecimento, relação da ciência e tecnologia com a sociedade, lógica e foco da política de ciência, tecnologia e sociedade.

A ideia de ciência como motor do progresso teve seu ápice no período entre o pós-Segunda Guerra Mundial e início dos anos 1960. A centralidade dessa concepção está baseada na visão de autonomia e neutralidade histórica e social da ciência. São os cientistas os que produzem o conhecimento a fim de garantir que ele seja livre de valores e influências sociais. A relação com a sociedade, nesse caso, é linear, pois tudo parte da ciência, que gera a tecnologia e, por fim, o benefício social. O foco é o fortalecimento da atividade de pesquisa por projetos individuais de livre escolha do pesquisador submetidos aos Conselhos de Pesquisa. Assim, a avaliação por pares, é considerada suficiente, não havendo necessidade de prestar contas à sociedade. ${ }^{4}$

Quanto à ciência como solução e causa de problemas, os movimentos sociais foram geradores dos questionamentos sobre a neutralidade da ciência. A produção do conhecimento ainda é responsabilidade dos cientistas, porém devem fazê-lo em grupos, de maneira a propiciar a articulação de saberes fundamentais à compreensão de uma realidade complexa. Apesar de os temas a ser abordados deverem responder a problemas relevantes para a sociedade, o foco é o mercado e a política tecnológica. Nesse sentido, o principal elemento influenciador são as demandas empresariais. As empresas são as possuidoras de conhecimentos e habilidades para julgarem que tipo de ciência se faz necessário. Assim, nesse paradigma, a ciência ainda é linear, porém o foco do desenvolvimento científico é influenciado pela priorização feita pelo setor produtivo. Ainda é central a avaliação por pares. ${ }^{4}$ 
A ciência como fonte de oportunidade estratégica concebe a ciência como construção social. A produção do conhecimento ocorre na relação entre múltiplos agentes (empresas, hospitais, ONGs, além do sistema acadêmico), em uma comunidade transepistêmica. Não há separação entre ciência e tecnologia, e sociedade. A ciência não é mais produzida de forma linear, havendo múltiplos atores para decidirem quanto à avaliação da política cientifica e tecnológica. O foco é a política de inovação. Sendo, por exemplo, financiadas atividades de pesquisa e desenvolvimento em empresas. Há um alargamento da revisão por pares, incluindo atores de fora da academia, e com análises de impacto social e econômico. ${ }^{4}$

A ciência para o bem da sociedade é um paradigma que ainda está em construção, e que admite que existem múltiplas formas de conhecimento. A ciência é culturalmente situada e construída, incorpora conhecimentos locais, abrindo espaço para visões nacionais e universais. Resulta de uma produção coletiva (participação de múltiplos atores, em redes de configuração variável, predominantemente interdisciplinar) com seus momentos de conflitos diante do encontro de saberes diversos. O foco é o bem-estar social, mas para isso a política científica e tecnológica deve apoiar a conectividade de múltiplos atores para garantir a participação social. Há desenvolvimento de mecanismos de avaliação de impactos sociais com participação social, além de avaliações sistêmicas. ${ }^{4}$

Apesar de cada um desses paradigmas ter se desenvolvido em períodos históricos diferentes, podemos perceber, ainda hoje, a presença de elementos de todos. Cada sujeito científico, na ação prática que desenvolve, contribui para que elementos desses paradigmas se expressem ou não. Por exemplo, os instrumentos de avaliação utilizados atualmente pelas agências de fomento à pesquisa tendem a ser de paradigmas anteriores. ${ }^{4}$

O processo de construção do conhecimento para transformação de si e da realidade passa pelo desafio de integrar a experiência vivida com ações na prática social. Tais desafios são compartilhados pela área de segurança alimentar e nutricional (SAN). Esta consiste na garantia do direito humano à alimentação adequada por meio de práticas alimentares saudáveis, que respeitem a cultura, sejam social, econômica e ambientalmente sustentáveis e não prejudiquem outros direitos. ${ }^{5}$ Nesse sentido, a área de SAN é uma área complexa e que apresenta diversos desafios de natureza estrutural a ser enfrentados, como: ampliar e fortalecer sistemas de produção de alimentos de bases sustentáveis; o aumento do excesso de peso e das doenças crônicas não transmissíveis; a garantia do acesso físico e financeiro de alimentos saudáveis a toda população; a insegurança alimentar e nutricional de populações tradicionais e outros grupos. ${ }^{6}$

Portanto, a extensão universitária na área de segurança alimentar e nutricional (SAN) traz em si o desafio e a possibilidade de um caminho para a construção de conhecimento compartilhado, que vise à transformação individual e coletiva, na articulação entre diferentes saberes e práticas. 
Durante o Seminário Nacional de Pesquisa em Segurança Alimentar e Nutricional ocorrido em 2012, a fala de Costa Gomes retrata como a construção de conhecimento e tecnologia pode articular diferentes saberes na área de SAN. ${ }^{7}$

A sabedoria popular tem relevante valor e deve ser reconhecida, embora não seja produzida em um contexto acadêmico-científico. Existem muitas tecnologias úteis produzidas pela pesquisa ou pela ciência convencional. O conhecimento dos agricultores e a experiência dos técnicos podem significar um novo estilo de conhecimento, e não a substituição de um conhecimento pelo outro. (...) É necessário defender a valorização da agrobiodiversidade do Brasil e dos conhecimentos a ela associados.

A construção de conhecimento na área de SAN é abordada na Política Nacional de Segurança Alimentar e Nutricional (PNSAN), instituída pelo Decreto no 7.272, de 2010, em que uma de suas diretrizes é o estabelecimento de "processos permanentes de educação alimentar e nutricional, pesquisa e formação nas áreas de segurança alimentar e nutricional e do direito humano à alimentação adequada". ${ }^{8}$

O segundo Plano Nacional de Segurança Alimentar e Nutricional (2016-2019) indicou a importância de ações relacionadas à pesquisa e à extensão em Segurança Alimentar e Nutricional na relação com o fortalecimento do Sistema de SAN: ${ }^{6}$

Além do fortalecimento dos componentes do Sistema faz-se importante promover as metas e ações relacionadas à pesquisa e extensão em SAN, à capacitação para o DHAA [direito humano à alimentação adequada], à construção dos mecanismos de exigibilidade do DHAA e ao aperfeiçoamento do sistema de monitoramento e indicadores da PNSAN.

A partir dos projetos e programas em SAN apresentados ao Programa Nacional de Extensão Universitária (Proext), pretende-se discutir, tendo como base a prática referenciada na SAN, como a extensão contribui para a construção do conhecimento e quais são os pressupostos para esta construção.

\section{Objetivos e Metodologia}

O objetivo deste estudo foi identificar pressupostos relacionados aos paradigmas da ciência para a construção de conhecimento nas propostas de extensão em SAN, financiadas por editais do Programa Nacional de Extensão Universitária . 
Foram identificados os projetos contemplados com recurso nos editais do Proext 2011, 2013 e 2014, que continham o termo "segurança alimentar e nutricional". O edital Proext, seus resultados e materiais de suporte ficam disponíveis no site do Ministério da Educação. As propostas das instituições de educação ficam arquivadas no banco de dados do Sistema de Informação e Gestão de Projetos (SIGProj), ao qual se solicitou acesso ao Ministério da Educação.

Após a identificação inicial, realizou-se a leitura dos títulos, linhas temáticas, subtemas que se relacionassem às diferentes dimensões previstas no conceito de segurança alimentar e nutricional conforme a Lei Orgânica de Segurança Alimentar e Nutricional (LOSAN), Lei nº 11.346/2006. ${ }^{5}$ Em seguida, tais propostas foram abertas no sistema do Ministério da Educação e Cultura (MEC) a fim de se realizar a leitura do texto integral das mesmas. Separou-se para análise apenas aquelas que continham no corpo do texto, no título, nas linhas temáticas ou nos subtemas, o termo "segurança alimentar e nutricional". Com esses critérios, foram selecionadas para análise documental por meio da análise de conteúdo, 116 propostas.

Segundo Cellard, ${ }^{9}$ análise documental é um método de coleta de dados por meio de documentos. Para este artigo, adota-se a concepção de documento ou "fonte" como sendo, segundo uma abordagem mais globalizante da história social, tudo o que é vestígio do passado, tudo o que serve de testemunho. São fontes exploradas (e não criadas) em um procedimento de pesquisa. As fases da análise de conteúdo englobam: pré-análise; exploração do material; e tratamento dos resultados: a inferência e a interpretação. ${ }^{10}$ Os parâmetros e eixos de análise dos documentos foram feitos conforme Velho ${ }^{4}$ sobre os paradigmas da ciência. A autora entende que o foco, os instrumentos e as formas de gestão que definem a política de ciência, tecnologia e inovação em um determinado momento são estreitamente relacionados com o conceito dominante de ciência. Assim, neste estudo, analisou-se nos projetos e programas Proext, as seguintes categorias empíricas: princípios da extensão em SAN; relação com a sociedade; foco da extensão em SAN; instrumentos/ estratégias da extensão em SAN.

Os princípios da extensão em SAN foram sistematizados conforme as seguintes categorias empíricas encontradas na análise dos documentos: diálogo com o saber local, a interdisciplinaridade, a valorização da diversidade/ética ambiental.

Sobre a relação com a sociedade, consideraram-se as influências para construir o conhecimento, incluindo a articulação com política pública, a relação com múltiplos atores e a articulação com o setor produtivo.

Quanto ao foco da extensão, esta foi analisada de acordo com as categorias de compromisso social/ transformação social (papel de educadores e educandos atuando na busca de transformação da realidade para o bem-estar social) e inovação (com base na na relação governo-universidadeindústria). 
E, por fim, os instrumentos/ estratégias das propostas de extensão em SAN foram categorizados conforme participação da comunidade na construção do conhecimento e transmissão/ difusão de conhecimento da academia para a sociedade.

A pesquisa foi aprovada pelo Comitê de Ética em Pesquisa da Universidade Federal de Brasília, com a emissão do Parecer no 788.097, em cumprimento à Resolução do Conselho Nacional de Saúde no 466, de 12 de dezembro de 2012, por estar incluída em um estudo mais amplo que previa a coleta de dados primários.

\section{Resultados}

Inicialmente, destaca-se que entre as 116 propostas analisadas, a maioria era da região Nordeste (acima de 40\%), seguida pela região Sudeste (24\%) e regiões Sul, Centro-Oeste, Norte (cada uma com cerca de 10\%). Em 54\% das equipes havia profissionais de duas a três áreas de conhecimento, indicando algum nível de multidisciplinaridade.

As propostas indicavam a relação com uma grande diversidade de grupos sociais, sendo o principal o dos agricultores familiares/ pequenos produtores (52\%), seguidos pelo dos estudantes da educação básica (27\%). No campo "áreas temáticas principais" preenchido pelos professores nos projetos e programas de SAN, destacaram-se: 22\% "saúde", 18\% "trabalho", 15\% "meio ambiente", 14\% "educação" e 3\% "direitos humanos e justiça". A interação com setores ou instituições para além das comunidades e do público interno ocorreu com governo municipal (71\%), estadual (56\%), federal (49\%), movimentos sociais (54\%), organizações não governamentais (50\%), sindicatos (40\%), instituições privadas (19\%).

Cerca de $90 \%$ das propostas de extensão em SAN financiadas nos três editais relatavam a intenção de aproximação academia-sociedade por meio do diálogo e/ou troca de saberes. 
Tabela 1. Princípios identificados nas propostas de extensão em Segurança Alimentar e Nutricional dos editais Proext. Brasil, 2011, 2013 e 2014.

\begin{tabular}{|c|c|c|c|c|}
\hline & $\begin{array}{c}\text { Proext } \\
2011 \\
(\text { Qtd/\%) }\end{array}$ & $\begin{array}{c}\text { Proext } \\
2013 \\
(\text { Qtd } / \%)\end{array}$ & $\begin{array}{c}\text { Proext } \\
2014 \\
(\text { Qtd } / \%)\end{array}$ & Exemplos \\
\hline \multicolumn{5}{|c|}{ Princípios } \\
\hline 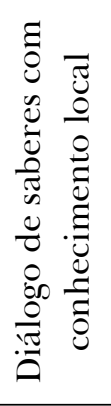 & $\begin{array}{l}28 \\
(90,3 \%)\end{array}$ & $\begin{array}{l}30 \\
(88,2 \%)\end{array}$ & $\begin{array}{l}46 \\
(90,2 \%)\end{array}$ & $\begin{array}{l}\text { Identificar e considerar os determinantes sociais } \\
\text { de saúde e as percepções existentes sobre os } \\
\text { processos de adoecimento, de desenvolver uma } \\
\text { troca de saberes técnico-científico-populares } \\
\text { entre acadêmicos e comunitários associada } \\
\text { ao desenvolvimento das ações programáticas } \\
\text { de educação em saúde. Proext 2013, IES } \\
\text { [Instituição de Ensino Superior] Amazonas. }\end{array}$ \\
\hline 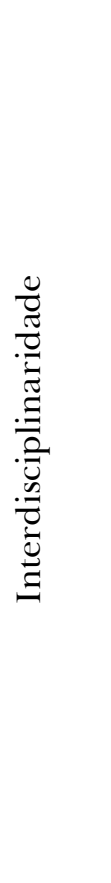 & $\begin{array}{l}26 \\
(83,8 \%)\end{array}$ & $\begin{array}{l}29 \\
(85,3 \%)\end{array}$ & $\begin{array}{l}43 \\
(84,3 \%)\end{array}$ & $\begin{array}{l}\text { Dará continuidade a sua estratégia geral de } \\
\text { produção do conhecimento (pesquisa) em } \\
\text { diferentes áreas, temas e aspectos da realidade } \\
\text { (economia solidária, relações de gênero, } \\
\text { finanças, consumo ético, responsável e solidário, } \\
\text { acesso a direitos de cidadania, segurança } \\
\text { alimentar e nutricional, resíduos e reciclagem), } \\
\text { buscando a integração com outras áreas de } \\
\text { conhecimento (educação popular, agroecologia, } \\
\text { habitação, saneamento ambiental, saúde coletiva } \\
\text { etc.) simultaneamente à intervenção (extensão) } \\
\text { na realidade social com formação (ensino) } \\
\text { de estudantes de diferentes cursos e níveis e } \\
\text { participação de vários tipos de profissionais } \\
\text { (arquitetura, ecologia, psicologia, sociologia, } \\
\text { engenharias, educação física, enfermagem, } \\
\text { terapia ocupacional, economia, biologia etc.). } \\
\text { Proext 2014, IES São Paulo. }\end{array}$ \\
\hline
\end{tabular}




\begin{tabular}{|c|c|c|c|c|}
\hline & $\begin{array}{c}\text { Proext } \\
2011 \\
(\text { Qtd } / \%)\end{array}$ & $\begin{array}{c}\text { Proext } \\
2013 \\
(\text { Qtd } / \%)\end{array}$ & $\begin{array}{c}\text { Proext } \\
2014 \\
(\text { Qtd } / \%)\end{array}$ & Exemplos \\
\hline 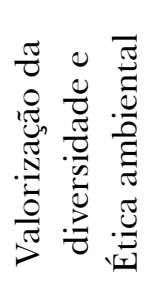 & $\begin{array}{l}21 \\
(67,7 \%)\end{array}$ & $\begin{array}{l}16 \\
(47 \%)\end{array}$ & $\begin{array}{l}24 \\
(47 \%)\end{array}$ & $\begin{array}{l}\text { Ampliar o número de agricultores(as) a utilizar } \\
\text { a biodiversidade e tecnologias apropriadas aos } \\
\text { sistemas de produção de base ecológica. Proext } \\
\text { 2011, IES Minas Gerais. }\end{array}$ \\
\hline
\end{tabular}

OBS $^{1}$ : O total de propostas analisadas varia por edital Proext, sendo 31 para o Proext 2011, 34 para o Proext 2013 e 51 para o Proext 2014. Os percentuais referem-se aos totais específicos dos editais.

$\mathrm{OBS}^{2}$ : As propostas podiam referenciar-se a mais de uma abordagem ou mesmo não referenciá-las. Portanto, o quantitativo é diferente do total de propostas analisadas, sendo o percentual diferente de $100 \%$.

Nos 116 projetos e programas de extensão em Segurança Alimentar e Nutricional analisados (Tabela 1), identifica-se a relevância das perspectivas relativas a princípios que valorizam o diálogo com o conhecimento local, predominantemente interdisciplinar e que leva em consideração a diversidade quanto aos recursos naturais.

A intenção de diálogo apontada pela grande maioria dos programas e projetos analisados, cerca de $90 \%$, é compatível com Freire. ${ }^{11}$ Para o autor, o diálogo não deve ser apenas um método, mas envolve uma relação social que pressupõe ação e reflexão. O diálogo, ao buscar a relação com as pessoas da comunidade, revela a crença nos homens e nas mulheres como seres capazes de pensar certo também. ${ }^{11}$ Vasconcelos \& Cruz, ${ }^{12}$ ao tratar da educação popular, reforçam a importância da solidariedade, da amorosidade, da organização e da autonomia dos sujeitos e dos grupos, em um movimento social de intelectuais, técnicos, lideranças populares engajados na transformação da sociedade de forma a superar pobreza e opressão. Boaventura de Souza Santos também resgata a importância do diálogo entre saberes científico e do senso comum, ${ }^{13}$ em que a dimensão utópica e libertadora do senso comum é aflorada no diálogo com o conhecimento científico. Visão similar é compartilhada por Leff, ${ }^{14}$ ao propor uma retotalização do saber por meio de um método interdisciplinar e a reinvenção de identidades por meio do diálogo de saberes (razão científica e saber popular), que transcende o projeto interdisciplinar. Eduardo Vasconcelos ${ }^{15}$ esclarece pontos de debate sobre os termos "interdisciplinaridade" e "transdisciplinaridade" que indicam, mas não esgotam, desafios dos fenômenos e as várias possibilidades de interação criativa entre campos de conhecimento e prática humana. As 'práticas inter-' significam a interação entre as fronteiras de campos de saber e fazer, tanto formais, como informais, como na interação com o campo da arte e com o senso comum e/ou cultura popular. 
Ainda nesse linha, Naomar ${ }^{16}$ entende que a transdisciplinaridade seria a "possibilidade de comunicação não entre campos disciplinares, mas entre agentes em cada campo, através da circulação não dos discursos (pela via da tradução), mas pelo trânsito dos sujeitos dos discursos". Portanto, seria o processo, estratégia de ação, modalidade da prática. O processo de construção de conhecimento científico deve ser cada vez mais social, político-institucional, matricial e amplificado.

Os projetos analisados indicam a busca pela interação entre disciplinas, pela interdisciplinaridade (mais de $80 \%$ ). Essa intenção de comunicação se manifesta pelo diálogo entre estes campos de saber-fazer, desde a relação com o senso comum e/ou cultura popular, e também com outros campos disciplinares como modalidade da prática da extensão, revelando a aproximação da perspectiva da transdisciplinaridade.

Tais princípios aproximam-se das propostas de ciência cidadã, ou militante, ou ciência para justiça ambiental. ${ }^{2}$ Em Velho, ${ }^{4}$ esta perspectiva é compatível com a concepção de ciência para o bem da sociedade. Acrescente-se que a perspectiva da interdisciplinaridade também se faz presente na concepção de ciência como oportunidade estratégica, revelando a possibilidade de coexistência dos paradigmas.

Na aproximação entre universidade e sociedade, e na interação entre diversos sujeitos com o contexto social e o meio ambiente, as propostas reforçam a necessidade de não fragmentação do conhecimento, diante da perspectiva da complexidade da segurança alimentar e nutricional. Assim, as práticas dos sujeitos da ciência na relação com a sociedade também incorporam suas práticas na relação com a natureza (cerca de $50 \%$ das propostas).

Nesse sentido, na área de SAN, e ainda nessa dimensão mais totalizadora, Leonardo Boff ${ }^{17}$ lembra que o que vale para o indivíduo vale também para a comunidade. Entende que o cuidado com o nicho ecológico só será efetivo se houver um processo coletivo de educação, em que a maioria participe, tenha acesso a informações e faça troca de saberes. O saber popular contido nas tradições dos velhos, nas lendas e nas histórias dos índios, caboclos, negros, mestiços, imigrantes dos primeiros que aqui viveram, confrontado e complementado com o saber crítico científico.

Ainda, na relação com a natureza e o ambiente, Altieri ${ }^{18}$ acrescenta a necessidade de se construir uma agricultura socialmente justa. Seriam questões-chave: levantar o que é produzido, como é produzido e para quem é produzido. Tais questões fariam emergir temas como posse da terra, mão de obra, tecnologia adequada, saúde pública, política de pesquisas etc. Esse fator se notou entre os projetos ao tentarem articular conhecimentos na busca da intersetorialidade e da interdisciplinaridade. Revela, assim, uma tentativa de articulação não apenas de disciplinas, mas de áreas de conhecimento científicas tradicionalmente fragmentadas na universidade, como a área de ciências da saúde e ciências agrárias. 
Assim, a concepção de ciência identificada na extensão em SAN indica que quem produz o conhecimento não é apenas a comunidade científica. Mais que isso, a tabela 2, a seguir, aponta que, na construção do projeto ou programa de extensão em SAN, o conhecimento é construído aproximando academia e sociedade de modo interativo com as políticas públicas, com múltiplos atores e, também, com o setor produtivo.

Tabela 2. Relação com a sociedade e influências sobre quem produz o conhecimento nas propostas de extensão em Segurança Alimentar e Nutricional nos editais Proext. Brasil, 2011, 2013 e 2014.

\begin{tabular}{|c|c|c|c|c|}
\hline \multicolumn{5}{|c|}{ Relação com a sociedade } \\
\hline Proext & $\begin{array}{c}2011 \\
(Q t d / \%)\end{array}$ & $\begin{array}{c}2013 \\
(Q t d / \%)\end{array}$ & $\begin{array}{c}2014 \\
(Q \operatorname{td} / \%)\end{array}$ & Exemplos \\
\hline 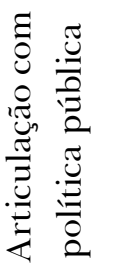 & $\begin{array}{l}10 \\
(32,2 \%)\end{array}$ & $\begin{array}{l}10 \\
(29,4 \%)\end{array}$ & $\begin{array}{l}24 \\
(47 \%)\end{array}$ & $\begin{array}{l}\text { Tem como objetivo central promover a saúde da } \\
\text { população. Vem ao encontro das diretrizes da } \\
\text { Política Nacional de Alimentação e Nutrição e } \\
\text { da Política Nacional de Segurança Alimentar e } \\
\text { Nutricional. Proext 2013, IES Santa Catarina. }\end{array}$ \\
\hline 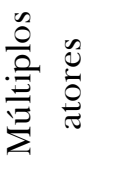 & $\begin{array}{l}11 \\
(35,5 \%)\end{array}$ & $\begin{array}{l}14 \\
(41,1 \%)\end{array}$ & $\begin{array}{l}18 \\
(35,3 \%)\end{array}$ & $\begin{array}{l}\text { Fortalecimento de redes de cooperação econômica } \\
\text { entre os EES [empreendimentos econômicos } \\
\text { solidários]. Proext 2014, IES Mato Grosso. }\end{array}$ \\
\hline 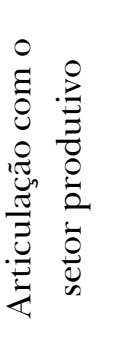 & $\begin{array}{l}23 \\
(74,2 \%)\end{array}$ & $\begin{array}{l}27 \\
(79,4 \%)\end{array}$ & $\begin{array}{l}31 \\
(60,7 \%)\end{array}$ & $\begin{array}{l}\text { Maior visibilidade dos produtos lácteos derivados } \\
\text { da agricultura familiar e inserção dos mesmos } \\
\text { no mercado institucional através das Exposições- } \\
\text { Feiras e das políticas governamentais (PAA - } \\
\text { Aquisição de Produtos da Agricultura Familiar e } \\
\text { PNAE - merenda escolar) bem como no mercado } \\
\text { consumidor privado. Proext 2014, IES Paraíba. }\end{array}$ \\
\hline
\end{tabular}

$\mathrm{OBS}^{1}$ : O total de propostas analisadas varia por edital Proext, sendo 31 para o Proext 2011, 34 para o Proext 2013 e 51 para o Proext 2014. Os percentuais referem-se aos totais específicos dos editais.

OBS²: As propostas podiam referenciar-se a mais de uma abordagem ou mesmo não referenciá-las. Portanto, o quantitativo é diferente do total de propostas analisadas, sendo o percentual diferente de $100 \%$. 
A abordagem sistêmica da SAN requer e favorece a relação com múltiplos atores para compreensão da realidade, solução de problemas e a concepção de políticas públicas intersetoriais e coordenadas, desde a produção, comercialização e consumo. ${ }^{19}$ Portanto, as relações estabelecidas na extensão, conforme ilustrado na tabela acima, potencializam a construção de um conhecimento que facilita o diálogo com as demandas sociais.

Schraiber ${ }^{20}$ contrapõe-se à visão predominante de uma necessária cisão entre o que é técnicocientífico e o que é ético-humano nas ações técnicas. Valoriza a dimensão subjetiva, o resgate de valores, o cuidado integral, mas também a responsabilidade social, do profissional, como agente técnico-científico, cidadão e sujeito da sociedade, na sua ação singular. Para contribuir com a promoção da saúde, Buss ${ }^{21}$ complementa ser necessário mais que o acesso a serviços médicoassistenciais de qualidade, sendo preciso enfrentar os determinantes da saúde em toda sua amplitude, o que requer políticas públicas saudáveis, uma efetiva articulação intersetorial do poder público e a mobilização da população.

A parceria com o mercado (cerca de 70\%) nas propostas Proext se apresentou pela inserção de cooperados ou agricultores no mercado formal, institucional (relacionado às políticas públicas) ou popular. Cabe o alerta de Silva ${ }^{22}$ de risco de a universidade ser lançada para o mercado para impulsionar o crescimento econômico e competitivo e se distanciar da possibilidade de promover emancipação humana, aproximando-a do paradigma de ciência como solução e causa de problemas. Entretanto, o que os projetos indicam com essa aproximação é a oportunidade de valorizar a produção local, em uma forma alternativa e contra-hegemônica de acercamento do mercado.

Na tabela 3, o foco da extensão em SAN aponta para uma universidade comprometida em apoiar a superação dos problemas do contexto em que se insere, procurando uma formação integral e transformação da sociedade na busca por seu bem-estar social (cerca de $60 \%$ das propostas). Ainda, esse foco é reforçado, mesmo que em poucos casos, com a possibilidade de desenvolvimento de instrumentos de participação social em 37\% das propostas (Tabela 4). Segundo Velho, ${ }^{4}$ o foco da ciência, tecnologia e inovação quando voltado ao bem-estar social deve assegurar a conectividade entre os múltiplos atores, garantindo a participação social.

As tabelas 2, 3 e 4 sugerem o reconhecimento em alguns projetos e programas de extensão da não linearidade na produção do conhecimento, em que há múltiplos atores envolvidos, em que as pessoas são sujeitos do processo e participam da procura por alternativas viáveis às situações sociais concretas nas quais se encontram. Assim, aproximam-se de uma ciência e tecnologia voltada para o bem da sociedade, a serviço do bem-estar social, da humanização.,11,13,14

Entretanto, percebe-se, conforme a tabela 3, que a relação com a inovação é identificada, ainda que de modo reduzido, nesse contexto estudado. Para Dagnino, ${ }^{23}$ a ideia de inovação é, de certa forma, contrária à proposta de tecnologia social, em que sua construção ocorre de modo 
participativo desde a concepção. A propriedade intelectual usualmente remete a uma motivação comercial, em que "a tecnologia não é escolhida para ser a melhor, mas se torna melhor porque é escolhida”. ${ }^{24}$ Portanto, aqui identificamos também a abordagem de uma ciência e tecnologia como fonte de oportunidade estratégica, voltada à política de inovação.

Tabela 3. Foco nas propostas de extensão em Segurança Alimentar e Nutricional apresentadas aos editais Proext. Brasil, 2011, 2013 e 2014.

\begin{tabular}{|c|c|c|c|c|}
\hline Proext & $\begin{array}{c}2011 \\
(\text { Qtd/\%) }\end{array}$ & $\begin{array}{c}2013 \\
(\text { Qtd/\%) }\end{array}$ & $\begin{array}{c}2014 \\
(\text { Qtd/\%) }\end{array}$ & Exemplos \\
\hline \multicolumn{5}{|r|}{ Foco } \\
\hline 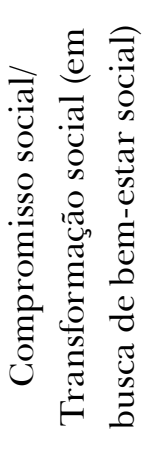 & $\begin{array}{l}18 \\
(53 \%)\end{array}$ & $\begin{array}{l}21 \\
(61,8 \%)\end{array}$ & $\begin{array}{l}34 \\
(66,6 \%)\end{array}$ & $\begin{array}{l}\text { Construir a consciência critica junto aos } \\
\text { estudantes, problematizando a formação } \\
\text { recebida nas universidades e a estrutura da } \\
\text { sociedade, colocando-os em contato com a } \\
\text { realidade agrária brasileira e com as perspectivas } \\
\text { de transformação desta através da organização } \\
\text { e mobilização social. Proext } 2014 \text {, IES Brasília. }\end{array}$ \\
\hline 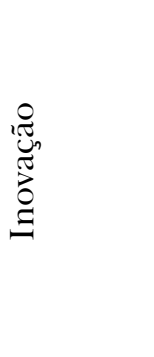 & $0(0 \%)$ & $0(0 \%)$ & $\begin{array}{l}2 \\
(3,9 \%)\end{array}$ & $\begin{array}{l}\text { Atuará através do oferecimento de capacitação } \\
\text { e formação em PI [propriedade intelectual] aos } \\
\text { membros da equipe, sobretudo na disseminação } \\
\text { da Ciência, Tecnologia e Inovação para a } \\
\text { Inclusão Social, objetivando o fortalecimento } \\
\text { da extensão tecnológica desta proposta. Proext } \\
\text { 2014, IES Bahia. }\end{array}$ \\
\hline
\end{tabular}

OBS': O total de propostas analisadas varia por edital Proext, sendo 31 para o Proext 2011, 34 para o Proext 2013 e 51 para o Proext 2014. Os percentuais referem-se aos totais específicos dos editais.

$\mathrm{OBS}^{2}$ : As propostas podiam referenciar-se a mais de uma abordagem ou mesmo não referenciá-las. Portanto, o quantitativo é diferente do total de propostas analisadas, sendo o percentual diferente de $100 \%$. 
Cardoso ${ }^{25}$ considera que a educação tecnológica deve contemplar a valorização do ser humano no processo, preparando-o para raciocinar sobre modelos produtivos, por meio de elementos críticos, para compreender a realidade da produção. Precisam ser consideradas as questões éticas e o custo social que o processo tecnológico acarreta, e não apenas econômico. Segundo Feenberg, ${ }^{26}$ para se ter algum controle sobre nossa própria humanidade, é preciso que se possa planejar e conduzir o desenvolvimento técnico por vários processos públicos e escolhas privadas.

Tabela 4. Estratégias/ Instrumentos para alcançar objetivos na extensão em Segurança Alimentar e Nutricional apresentadas aos editais Proext. Brasil, 2011, 2013 e 2014.

\begin{tabular}{|c|c|c|c|c|}
\hline Proext & $\begin{array}{c}2011 \\
(\text { Qtd/\%) }\end{array}$ & $\begin{array}{c}2013 \\
(\text { Qtd/\%) }\end{array}$ & $\begin{array}{c}2014 \\
(\text { Qtd/\%) }\end{array}$ & Exemplos \\
\hline \multicolumn{5}{|c|}{ Estratégias/ Instrumentos } \\
\hline 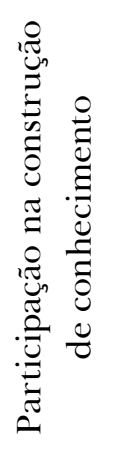 & $\begin{array}{l}12 \\
(38,7 \%)\end{array}$ & $8(23 \%)$ & $\begin{array}{l}17 \\
(33,3 \%)\end{array}$ & $\begin{array}{l}\text { Será desenvolvido através de metodologia } \\
\text { participativa, onde os integrantes atuarão } \\
\text { em todas as etapas do projeto, estimulando } \\
\text { a mobilização, a valorização dos saberes e a } \\
\text { criatividade dos participantes. Proext 2014, IES } \\
\text { Mato Grosso do Sul. }\end{array}$ \\
\hline 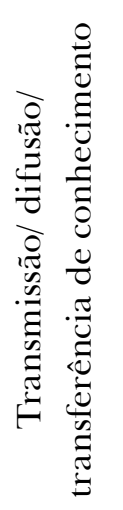 & $\begin{array}{l}18 \\
(58 \%)\end{array}$ & $\begin{array}{l}21 \\
(61,8 \%)\end{array}$ & $\begin{array}{l}28 \\
(54,9 \%)\end{array}$ & $\begin{array}{l}\text { É também necessário que se faça o registro das } \\
\text { atividades desenvolvidas para que isso possa ser } \\
\text { utilizado nas diferentes atividades de divulgação, } \\
\text { transferência de tecnologia e treinamentos. } \\
\text { Proext 2011, IES Paraná. }\end{array}$ \\
\hline
\end{tabular}

OBS 1 : O total de propostas analisadas varia por edital Proext, sendo 31 para o Proext 2011,34 para o Proext 2013 e 51 para o Proext 2014. Os percentuais referem-se aos totais específicos dos editais.

$\mathrm{OBS}^{2}$ : As propostas podiam referenciar-se a mais de uma abordagem ou mesmo não referenciá-las. Portanto, o quantitativo é diferente do total de propostas analisadas, sendo o percentual diferente de $100 \%$. 
Percebe-se que coexistem visões diferentes na extensão em SAN que implicam diferentes paradigmas. A perspectiva de transmissão de conhecimento (Tabela 4) remete a concepções de ciência mais linear (iniciando-se com a ciência até produzir bem-estar social). Nesse caso, o paradigma estaria mais relacionado à concepção de ciência como motor do progresso. Exemplos a seguir demonstram a simplificação da problematização e do diálogo a uma mera troca de informações, complementada com ações mais voltadas à difusão ou a transferências tecnológicas e de conhecimento. Esta perspectiva talvez possa ser entendida como um primeiro passo para se conseguir avançar na construção de conhecimento novo com a comunidade. Abaixo, exemplos presentes nas propostas revelam a busca por abordagens que envolvam maior compromisso e participação da comunidade, porém com a presença de elementos que indicam a contradição dessas teorias com as práticas de difusão ou transferência de informação unidirecional:

Abordagem dos temas será feita a partir da pedagogia da problematização, isto é, partindo da troca de informações com os participantes sobre a realidade das condições de vida da sua comunidade (...) transferência de conhecimentos técnico-científicos para a população (...) estratégias para difusão da cultura da inovação. Proext 2014, IES [Instituição de Ensino Superior] Bahia.

Parceria com os agricultores viabilizará/facilitará a transferência de tecnologias e conhecimento (...) transferência de tecnologias para a produção (...) visando à melhoria da competitividade e condições de vida (...) difusão de tecnologias adaptadas a realidade local (...) difundir tecnologias oriundas de resultados de pesquisa. Proext 2014, IES Mato Grosso.

Outras propostas já apresentaram elementos que indicam um diálogo com a realidade e potencialidades locais, como, por exemplo:

uso de sal temperado, elaborado com ervas/condimentares produzidas na horta das escolas para temperar os alimentos, e incrementar a alimentação escolar com produto cárneo adicionado com farinha de feijão (Phaseolusvulgaris L.), sendo o feijão adquirido de produtores locais (grifo nosso). Proext 2014, IES Rio Grande do Sul.

Na extensão universitária, essas soluções criativas são estimuladas e potencializadas por meio do diálogo e da participação na relação com o outro, levando à possibilidade de uma práxis criativa. ${ }^{27}$ Essa práxis no Proext ocorre pela articulação intersetorial, com vários atores, por meio do diálogo de saberes e valorização do conhecimento tradicional, na busca por alternativas viáveis, e pela ação política por meio de políticas públicas. Assim, ao considerar o todo, aproxima-se de uma abordagem integral de educação e de uma ciência e tecnologia que visa ao bem da sociedade.

Das 116 propostas analisadas dos Proext 2011, 2013 e 2014, 53\% relatavam desenvolvimento, transferência ou construção social de tecnologia. Segundo Grinspun,,$^{28} \mathrm{em}$ termos de educação para viver a era tecnológica, há que se pensar como o indivíduo se posiciona ante a sua identidade, 
mas também ante as situações que o circundam. Este pode criar, usar, transformar as tecnologias, mas sem se ausentar, desconhecendo os perigos, desafios e desconfortos que a própria tecnologia pode acarretar. Como afirma Saviani, ${ }^{29}$ "o ato educativo sempre carrega consigo determinado conteúdo político", e a prática do professor, tenha ele consciência ou não, tem um sentido político em si. Há propostas identificadas que tentaram, como abaixo, relacionar os princípios da tecnologia social ao da inovação, revelando aproximação com a concepção de ciência como fonte de oportunidade estratégica. ${ }^{4}$

Desenvolver uma tecnologia social que produzirá inovação para superar a insegurança alimentar e nutricional na comunidade escolar. Proext 2014, IES Amazonas.

Na atualidade, segundo Moretti, ${ }^{30}$ a inserção do indivíduo na sociedade do conhecimento sem vistas à transformação social aliena o sujeito ao alinhá-lo à sociedade capitalista. O saber deixa de ser mediação do homem para formação humana, ocupando o papel de mercadoria.

Por outro lado, identifica-se nos projetos e programas Proext analisados a busca por tecnologias que facilitem autonomia e empoderamento. Por exemplo, nos relatos a seguir:

Incubadora de Tecnologia Social para Segurança alimentar e Nutricional (...) como um espaço para assessoria e apoio (...) possam gerar aplicações de tecnologias sociais associada a grupos sociais específicos organizados mediante empreendimentos econômicos solidários [EES]. Proext, 2013, IES Brasília.

Todas as tecnologias propostas para as ações serão construídas em campo, a partir de um conjunto de atividades em grupo, envolvendo profissionais e estudantes de diversas áreas, bem como agricultores familiares em geral (...) levando juntamente uma ação pedagógica em campo (...) atendendo (...) [a] interação entre ensino, pesquisa e extensão. (...) As tecnologias (...) serão planejadas, construídas, instaladas a partir do protagonismo dos atores locais. Proext 2014, IES Pernambuco.

Na tríade ciência-tecnologia-sociedade, a educação tem lugar de destaque pelo que produz, desenvolve, mas, sobretudo, pelo que pode construir. A educação tecnológica deve considerar que a formação do indivíduo dê-lhe condições para propiciar a criação de tecnologias. $\mathrm{O}$ comprometimento deve ser maior com o processo e não apenas com o produto ou resultado final da tecnologia, deve relacionar a tecnologia com o cotidiano do trabalho do indivíduo, deve despertar um lado humanístico da tecnologia, valorizando o mundo subjetivo. ${ }^{28}$

Identificou-se nos projetos e programas Proext, uma abordagem da SAN envolvendo a sustentabilidade (agroecologia), a solidariedade (cooperativismo, EES), a autonomia local de pequenos produtores ("independência das famílias", "protagonismo"), o consumo saudável (agroecologia, alimentação saudável) e o incentivo à alimentação regional. Além disso, buscam 
prestar assistência técnica visando à qualidade de alimentos, sistematização de cadeia de produção e agregação de valor, em organização em rede coletiva de produtores.

Percebe-se, portanto, a opção por tecnologias sociais, ou mais especificamente, aquelas que propõem alternativas às convencionais. A proposta de tecnologia social ou alternativa é uma forma de resistência à tecnologia convencional, estando em seu alicerce a solidariedade e a participação dos produtores/ usuários. As teorias e as tecnologias possibilitariam soluções para vários problemas, e seriam os atores sociais os sujeitos responsáveis pela decisão final acerca de uma série de opções tecnicamente possíveis, sendo que a própria definição do problema mudaria ao longo do processo para sua solução. ${ }^{23}$ Relaciona-se à metáfora de tecido sem costura, em que o conjunto de elementos técnicos e sociais resulta em algo mais que a soma desses elementos. Assim, a tecnologia poderia alavancar um estilo alternativo de desenvolvimento, pois o desenvolvimento tecnológico não é linear, mas pode se ramificar em muitas direções e projetos alternativos, reprojetando os interesses científicos e tecnológicos às demandas e interesses dos atores sociais.

Ainda, na área pedagógica, as universidades utilizam tecnologias da informação para educação em SAN. O exemplo a seguir demonstra o uso dessa linguagem:

Rede de tecnologia social (...) com a temática da alimentação escolar. Esse processo gera um grupo fortalecido de atores que podem modificar a realidade social a partir das trocas de experiências e saberes, bem como gerar caminhos e processos para o monitoramento do direito humano à alimentação e além de possibilitar a construção de um modelo coletivo e participativo (...) Outro parceiro (...) é o telenutrição (...) se utiliza a internet como ferramenta (...) o blog (...). Trata-se de um espaço virtual em que esperamos ser possível manter fóruns de debate sobre questões polêmicas, troca de experiências exitosas. Proext 2013, IES Rio de Janeiro.

No texto acima, o uso da internet pode contribuir para a construção de conhecimento para articulação de coletivos e debates críticos que possibilitem a ampliação da consciência dos envolvidos. A multimídia implica a noção do movimento fluido de uma dimensão (tempo) para outro (espaço), em que se busca maneiras diversificadas de linguagem para construção coletiva de conhecimento e diálogo entre saberes individuais e coletivos. Entretanto, cabe problematizá-la, pois é fundamental que ocorra um processo de construção de uma identidade consciente do seu tempo e de sua realidade para não correr o risco de se ter uma legião de internautas com plena apropriação das ferramentas da cibercultura, mas totalmente alienados e sem consciência crítica. Por outro lado, as tecnologias da informação podem reconhecer o aprender como práxis do fazer, para formação integrada como fonte de experiência coletiva e de uma aprendizagem significativa. Desse modo, colaboraria para a construção subjetiva dos sujeitos, além de possibilitar mudanças pelo compartilhamento de experiências. A universidade pode, ainda, desenvolver-se como espaço de ação e reflexão sobre a realidade, e considerar aspectos locais e globais. A integração das linguagens do 
ciberespaço, da cultura popular e científica pode ampliar habilidades e competências dos sujeitos para desvelar o contexto por intermédio de novas práticas sociais dentro e fora da universidade. Dessa maneira, possibilitaria o despertar político e cultural no sujeito para que ele possa ampliar o processo de conscientização acerca de si e do mundo. Portanto, para que possam criar, pensar e se articular pela emancipação política e social no exercício de sua cidadania. ${ }^{31}$ Assim, a relação com o conhecimento implica uma práxis criativa.

Algumas propostas remetem a abordagens mais dialógicas, entretanto, outras se fundamentam em abordagens difusionistas, de transferência tecnológica ou de conhecimento, em detrimento ou em contraposição a ações mais comprometidas não apenas com a linguagem popular e sua participação ou mero diálogo ingênuo, mas com a possibilidade de uma reflexão transformadora sobre a situação problema. Revelam, assim, a coexistência de paradigmas diferenciados nas propostas de extensão em SAN, algumas vezes com contradições entre teorias e práticas dentro dos próprios projetos e programas.

Um paradigma se torna dominante por meio de uma luta pela hegemonia que se trava no campo disciplinar ocupado pelos sujeitos históricos, condutores e conduzidos pela prática científica. ${ }^{16}$ Portanto, a SAN entendida enquanto um objeto complexo compreende produtos culturais resultantes de uma prática social. Diante das análises, compartilhamos com Faria, ${ }^{32}$ que acredita que a extensão universitária está presa em dois caminhos contraditórios. Em uma direção, busca a superação de si mesma como instrumento articulador que produz transformações tanto intramuros como extramuros; em outra direção, pode servir a interesses de manutenção de classes hegemônicas. Assim, deve estar em constante reflexão sobre sua prática, sobre o modelo de universidade e de sociedade que almeja.

\section{Conclusão}

Ao considerar as propostas submetidas aos editais Proext, a construção de conhecimento e de tecnologia na área de Segurança Alimentar e Nutricional se mostra como objeto complexo articulado à prática social. A extensão em SAN estimula uma abordagem integral de educação, com aproximação de uma Ciência, Tecnologia para o bem da Sociedade, que busca, por meio do diálogo de saberes, a valorização do conhecimento local, o incentivo à mobilização coletiva, à participação, o envolvimento com políticas públicas e a construção de alternativas tecnológicas ao sistema agroalimentar dominante. Apesar disso, percebe-se que convivem entre os projetos e programas de extensão em SAN paradigmas diferentes quanto à ciência e tecnologia. Alguns discursos apresentam modelos de produção do conhecimento pela lógica do mercado, ou revelam contradição entre teorias dialógicas e práticas mais voltadas à transmissão de conhecimentos ou tecnologias. Essas abordagens podem gerar resistências quanto à incorporação de novos saberes e tecnologias, devido à redução da autonomia e liberdade dos sujeitos das comunidades nos processos. 
O estudo sobre a extensão em SAN reforça a importância de vinculação da academia à realidade local e à construção de um conhecimento em SAN adequado às necessidades sociais e comprometido com a solução de problemáticas locais. No entanto, cabe à universidade continuar e aprofundar a reflexão sobre os princípios que norteiam suas práticas, a relação de proximidade com a sociedade na construção do conhecimento, a fim de esclarecer para que e a quem suas práticas servem.

\section{Colaboradores}

EMP contribuiu na concepção, metodologia, coleta, análise, interpretação e na redação final. ER, no desenho da metodologia, revisão crítica e redação final do artigo.

Conflito de interesses: Os autores declaram não haver conflito de interesses.

\section{Agradecimentos}

Agradecemos a colaboração de Samara Cabral Rodrigues, pela contribuição na sistematização dos documentos.

\section{Referências}

1. Fórum de Pró-Reitores de Extensão das Universidades Públicas Brasileiras. Política Nacional de Extensão Universitária. Manaus: Forproex; 2012. 66 p.

2. Santos BS. Um olhar sobre o dossiê a partir da ecologia de saberes. In: Carneiro FF, Rigotto RM, Augusto LGDS, Friedrich K, Burigo AC. Dossiê ABRASCO: um alerta sobre os impactos dos agrotóxicos na saúde. Rio de Janeiro: EPSJV; São Paulo: Expressão Popular; 2015. p .198-203.

3. Minayo MCS. Avaliação por triangulação de métodos: abordagem de programas sociais. Rio de Janeiro: Editora Fiocruz; 2005. 244 p.

4. Velho L. Conceitos de ciência e a política científica, tecnológica e de inovação. Sociologias 2011; 13(26):128-153.

5. Brasil. Lei no 11.346 de 15 de setembro de 2006. Cria o Sistema Nacional de Segurança Alimentar e Nutricional. Diário Oficial da União 18 set. 2006; Seção 1:1.

6. Brasil. Câmara Interministerial de Segurança Alimentar e Nutricional. Plano Nacional de Segurança Alimentar e Nutricional - PLANSAN 2016-2019. Brasília: MDSA, CAISAN; 2017.

7. Brasil. Conselho Nacional de Segurança Alimentar e Nutricional. Relatório Final do Seminário de Pesquisa em SAN. Brasília: Consea; 2014.

8. Brasil. Decreto $n^{\circ} 7.272$, de 25 de agosto de 2010. Estabelece os parâmetros para a elaboração do Plano Nacional de Segurança Alimentar e Nutricional. Diário Oficial da União 26 ago. 2010. 
9. Cellard A. Análise documental. In: Poupart J, Deslauriers JP, Groulx LH, Laperrieère A, Mayer R, Pires AP, organizadores. A pesquisa qualitativa: enfoques epistemológicos e metodológicos. Petrópolis: Vozes; 2012. p. 295-316.

10. Bardin. Análise de conteúdo. Lisboa: Edições 70; 1977. 226 p.

11. Freire P. Pedagogia do oprimido. 54a ed. rev. e atual. Rio de Janeiro: Paz e Terra; 2013. 236 p.

12. Vasconcelos EM, Cruz PJ, organizadores. Educação popular na formação universitária: reflexões com base em uma experiência. São Paulo: Hucitec; João Pessoa: Editora Universitária da UFPb; 2011. 420p.

13. Santos BS. Um discurso sobre as ciências. 6a ed. São Paulo: Cortez; 2009. 92 p.

14. Leff E. Aventuras da epistemologia ambiental: da articulação das ciências ao diálogo de saberes. Rio de Janeiro: Garamond; 2004. 85 p.

15. Vasconcelos E. Epistemologia, diálogos e saberes: estratégias para práticas interparadigmáticas em saúde mental. Cad Bras Saúde Mental 2011; 1(1):119-129.

16. Almeida Filho N. Transdisciplinaridade e o paradigma pós-disciplinar na saúde. Saúde Soc. 2005; 14(3):30-50.

17. Boff L. Saber cuidar: ética do humano: compaixão pela terra. 15 ed. Petrópolis: Vozes; 2008. 200 p.

18. Altieri M. Agroecologia: a dinâmica produtiva da agricultura sustentável. $5^{\mathrm{a}}$ ed. Porto Alegre: Editora da UFRGS; 2005. 120 p.

19. Maluf RS, Burlandy L, Santarelli M, Schottz V, Speranza JS. Nutrition-sensitive agriculture and the promotion of food and nutrition sovereignty and security in Brazil. Ciênc. Saúde Coletiva 2015; 20(8):2303-2312.

20. Schraiber LB. No encontro da técnica com a Ética. Interface-Comunicação, Saúde, Educação 1997; 1(1):123-138.

21. Buss PM. Promoção da saúde e qualidade de vida. Ciênc Saúde Coletiva 2000; 5(1):163-177.

22. Silva MA. Os limites da expressão sociedade do conhecimento e interfaces com a política educacional. In: Cunha C, Sousa JV, Silva MA, organizadores. Universidade e educação básica: políticas e articulações possíveis. Brasília: Liber Livro-Faculdade de Educação da UnB; 2012. p. 311-331.

23. Dagnino RP, organizador. Tecnologia social: ferramenta para construir outra sociedade. Campinas: IG/Unicamp; 2009. 183 p.

24. Dias RB, Novaes HT. Contribuições da economia da inovação para a reflexão acerca da tecnologia social. In: Dagnino RP, organizador. Tecnologia social: ferramenta para construir outra sociedade. Campinas: IG/Unicamp; 2009. p. 40-60.

25. Cardoso TF. Sociedade e desenvolvimento tecnológico: uma abordagem histórica. In: Grispun MZ. Educação tecnológica: desafios e perspectivas. São Paulo: Cortez; 1999. p. 183-225.

26. Feenberg A. Teoria crítica da tecnologia [Internet] Canadá: Simon Fraser University; 2009. [acesso em: 27 jun. 2017]. Disponível em: http://www.sfu.ca/ andrewf/critport.pdf

27. Vázquez AS. Filosofia da práxis. Rio de Janeiro: Paz e Terra; 1977. 453p. 
28. Grinspun MZ. Educação tecnológica: desafios e perspectivas. São Paulo: Cortez; 1999. 294 p.

29. Saviani D. Pedagogia histórico-crítica: primeiras aproximações. 11 ed. rev. Campinas: Autores associados; 2012. $137 \mathrm{p}$.

30. Moretti VD. A teoria do valor em Marx e a educação: um olhar sobre a pedagogia das competências. In: Paro VH. A teoria do valor em Marx e a educação. $2^{a}$ ed. São Paulo: Cortez; 2013. p. 203-213.

31. Rodrigues DV, Porto FC. A construção coletiva da aprendizagem na transiarte: das linguagens artísticas à cultura tecnológica. In: Reis RH, Castioni R, Teles L, organizadores. Proeja-transiarte: construindo novos sentidos para a educação de jovens e adultos trabalhadores. Brasília: Verbena; 2012. p. 138-172.

32. Faria DS, organizadora. Construção conceitual da extensão universitária na América Latina. Brasília: Universidade de Brasília; 2001. p.186. 
